\title{
Novel Acrylic Adhesive for Transdermal Drug Delivery
}

\author{
Susumu Maruo, Hiroyoshi Minematsu, and Takeyuki Kawaguchi \\ TEIJIN LIMITED, Polymer Research Institute, \\ 2-1 Hinode-cho, Iwakuni, Yamaguchi 740-8511, Japan
}

(Received July 1, 1999)

\begin{abstract}
KEY WORDS Poly(ethylene glycol)acrylate / Cross-Linking / Adhesive / Water Vapor Permeability /
Transdermal Drug Delivery /
\end{abstract}

In recent years, transdermal drug delivery(TDD) has been intensively investigated and applied as a practical therapeutic system because of the avoidance of first-pass gastrointestinal and hepatic metabolism, decrease of side effects and improvement of patient compliance. There is a typical case of skin irritation caused by maceration of the skin covered with the adhesives in TDD patch with low water vapor permeability (WVP). ${ }^{1,2}$

To avoid the skin maceration, some modification of acrylic adhesives by introducing hydrophilic group, such as poly(ethylene glycol) groups, into the adhesive molecules has been reported to enhance WVP. Other trials to copolymerize poly(ethylene glycol)acrylates with 2ethylhexyl acrylate and a small amount of acrylic acid are also reported. ${ }^{3,4}$ These trials have been partly successful in that a small amount of poly(ethylene glycol) group was introduced into the adhesive polymer. Bo et al . report that poly(ethylene glycol)monomethacrylates easily formed unprocessable cross-linked gels in radical polymerization because of chain transfer reaction. ${ }^{5}$

This study investigates the feasibility of prevention of cross-linking of the adhesives with high WVP by substituent groups at the end of poly(ethylene glycol)moiety. WVP and peel-off strength of the obtained adhesive polymers as the TDD were also studied.

\section{EXPERIMENTAL}

\section{Materials}

Ethyl acetate, 2-ethylhexylacrylate, tetrahydrofuran (THF) and acetonitrile were purchased from Kanto Chemicals Co., Inc. Acrylic acid was purchased from TOKYO KASEI KOGYO Co., Ltd. Ethyl acetate, 2ethylhexylacrylate and acrylic acid were distilled before use. 2,2'-Azobisisobutyronitrile(AIBN) was purchased from Wako Pure Chemical Industries, Ltd. Poly(ethylene glycol) acrylate(PEGA), poly(ethylene glycol)methyl ether acrylate(PEGMA), poly(ethylene glycol) butyl ether acrylate(PEGBA), poly(ethylene glycol) octyl ether acrylate(PEGOA), and poly(ethylene glycol) lauryl ether acrylate(PEGLA) were supplied from NOF corporation. Poly(ethylene glycol) phenyl ether acrylate(PEGPA) and poly(ethylene glycol) nonyl phenyl ether acrylate (PEGNPA) were supplied from TOAGOSEI Co., Ltd. The average degree of ethylene glycol polymerization of these monomers was four. The monomers with poly(ethylene glycol)moiety were used for polymerization without further purification.

\section{Polymerization}

Polymerization was carried out under the following conditions : monomers $(30 \mathrm{~g})$ (see Table I for details), ethyl acetate $(30 \mathrm{~g})$ and $\operatorname{AIBN}(0.3 \mathrm{~mol} \%$ to monomers $)$ were added to a $200 \mathrm{~mL}$ glass flask and the solution was bubbled with nitrogen for $1 \mathrm{~h}$ and heated at $70^{\circ} \mathrm{C}$ for $2-$ $6 \mathrm{~h}$ under nitrogen atmosphere.

Number and weight average molecular weights of the polymers were measured by GPC using Shodex System 11 equipped with GPC column(KF-80 M, SHOWA DENKO) with length of $1.2 \mathrm{~m}$. GPC was operated using THF as eluent and flow rate of $1.0 \mathrm{~mL} \mathrm{~min}^{-1}$ at $40^{\circ} \mathrm{C}$.

\section{Preparation of Adhesive Layer}

To measure WVP and peel strength of polymers, the adhesive layer was prepared as follows. The ethyl acetate solution obtained after ethyl acetate $(5 \mathrm{~g})$ was added to the polymer solution $(10 \mathrm{~g})$ obtained above was casted on poly(ethylene terephthalate) (PET) film coated by poly(dimethyl siloxane) at a dry thickness of $40 \mu \mathrm{m}$ using a doctor blade and dried at $60^{\circ} \mathrm{C}$ for $30 \mathrm{~min}$.

\section{Measurement of Water Vapor Permeability (WVP)}

The adhesive layers obtained above were transferred to the polyester non-woven fabric substrate with WVP of $8000 \mathrm{~g} \mathrm{~m}^{-2}$ day $^{-1}$. Each sample was mounted on the glass cup with $38 \mathrm{~mm}$ i.d. containing $26 \mathrm{~g}$ of $\mathrm{CaCl}_{2}$. It settled down in the thermo-hygrostat(LH 20-11,NAGANO SCIENCE Corporation) at $40^{\circ} \mathrm{C}$ with $90 \%$ relative humidity for $3 \mathrm{~h}$. WVP was calculated from the weight increase of $\mathrm{CaCl}_{2}$.

\section{Measurement of Peel Strength}

The adhesive layers were transferred to the polyester film of $3.5 \mu \mathrm{m}$ thickness backed with surgical tape(Micropore 1530-3, $3 \mathrm{M}$ Health Care Co.). Each sample was cut into $12 \mathrm{~mm} \times 50 \mathrm{~mm}$ size and attached to a bakelite plate. After kept at $37^{\circ} \mathrm{C}$ for $30 \mathrm{~min}$., they were peeled in the horizontal direction at the speed of $300 \mathrm{~mm} \mathrm{~min}^{-1}$ using the tensile tester(Tensilon RTC-1210 A, ORIENTEC Corporation).

\section{RESULTS AND DISCUSSION}

\section{Effect of Substituent Group}

To synthesize the adhesive with poly(ethylene glycol) unit, various poly(ethylene glycol) acrylates were copolymerized with 2-ethylhexyl acrylate and a small amount of acrylic acid, which are generally used as the 
Table I. Results of copolymerization of poly(ethylene glycol) acrylate derivatives $^{\text {a }}$

\begin{tabular}{|c|c|c|c|c|c|}
\hline \multirow{2}{*}{ No. } & \multirow{2}{*}{$\begin{array}{l}\text { Monomer } \\
\text { (1) }\end{array}$} & \multirow{2}{*}{$\begin{array}{l}\text { Substitution group } \\
(\mathrm{R})\end{array}$} & \multicolumn{3}{|c|}{ Monomer content/wt\% } \\
\hline & & & 15 & 30 & 45 \\
\hline 1 & PEGA & $-\mathrm{H}$ & Gel & Gel & - \\
\hline 2 & PEGMA & $-\mathrm{CH}_{3}$ & No gel & Gel & - \\
\hline 3 & PEGBA & $-\left(\mathrm{CH}_{2}\right)_{3} \mathrm{CH}_{3}$ & - & No gel & No gel \\
\hline 4 & PEGOA & $-\left(\mathrm{CH}_{2}\right)_{7} \mathrm{CH}_{3}$ & - & No gel & No gel \\
\hline 5 & PEGLA & $-\left(\mathrm{CH}_{2}\right)_{11} \mathrm{CH}_{3}$ & - & No gel & No gel \\
\hline 6 & PEGPA & $-\mathrm{Ph}$ & Gel & Gel & - \\
\hline 7 & PEGNPA & $-\mathrm{Ph}-p-\left(\mathrm{CH}_{2}\right)_{8} \mathrm{CH}_{3}$ & Gel & Gel & - \\
\hline
\end{tabular}

${ }^{a}$ Comonomers were 2-ethylhexyl acrylate (50-80 wt $\%$ ) and 5 wt $\%$ of acrylic acid. Polymerization time was $6 \mathrm{~h}$.

monomer to give adhesion and cohesion for the TDD adhesive(Scheme I ). Poly(ethylene glycol) acrylate easily forms cross-linked gel in radical polymerization by the chain transfer. ${ }^{5}$ As shown in Table I, copolymers with high content of poly(ethylene glycol) unit were obtained by copolymerizing butyl, octyl and lauryl substituted poly(ethylene glycol) acrylate monomers. The poly(ethylene glycol) acrylate monomers with phenyl, nonylphenyl and hydrogen substituent easily formed gel at $15 \mathrm{wt} \%$ content in the monomers and the monomer with methyl substituent formed gel at $30 \mathrm{wt} \%$ content. Butyl, octyl and lauryl substituted monomer did not give a gel even at $45 \mathrm{wt} \%$ content. These results indicate that prevention of gel formation decreases in the order of lauryl, octyl, butyl $>$ methyl $>$ phenyl, nonylphenyl and hydrogen.

Although phenyl or nonylphenyl groups are large substituent group like lauryl or octyl, they easily showed gel formation. This indicates that steric effect of substituted group is not important for preventing gel formation.

Electron release of substituent thus appears more effective than steric effect to prevent the gel formation by chain transfer.

\section{Peel Strength and WVP of PEGLA Copolymers}

Since solubility of drug is very important for TDD adhesive as well as WVP, we evaluated the properties of PEGLA copolymers which contain surfactant structure. Peel strength and characterization of the copolymers with various PEGLA content $(0,20,40 \mathrm{wt} \%)$ are shown in Table II. The copolymer possesses similar molecular weight $\left(M_{w}, M_{w} / M_{n}\right)$ and almost the same peel strength with good cohesion. PEGLA may thus have adhesive properties like 2-ethylhexylacrylate by itself.

WVP of PEGLA copolymers were investigated by

Table II. Characterization and properties of PEGLA ${ }^{\mathrm{a}}$ copolymers ${ }^{\mathrm{b}}$

\begin{tabular}{cccccc}
\hline No. & $\begin{array}{ccccc}\text { PEGLA content } \\
\text { wt\% }\end{array}$ & $\begin{array}{c}M_{\mathrm{w}}^{\mathrm{c}} \\
\left(10^{-5}\right)\end{array}$ & $M_{w} / M_{n}$ & $\begin{array}{c}\text { Peel strength } \\
(\mathrm{g} / 12 \mathrm{~mm})\end{array}$ & $\begin{array}{c}\text { WVP } \\
\mathrm{g} \mathrm{m}^{-2} \mathrm{day}^{-1}\end{array}$ \\
\hline 1 & 40 & 3.03 & 4.8 & 505 & 780 \\
2 & 20 & 4.33 & 5.2 & 558 & 500 \\
3 & 0 & 4.31 & 4.4 & 497 & 390 \\
\hline
\end{tabular}

apoly(ethylene glycol) laurylether acrylate. ${ }^{b}$ Comomomers were 2 -ethylhexyl acrylate $(45-85 \mathrm{wt} \%)$ and $15 \mathrm{wt} \%$ of acrylic acid. Polymerization time was $6 \mathrm{~h}$ except No.3( $2 \mathrm{~h})$. ${ }^{\mathrm{c}}$ Determined by GPC.

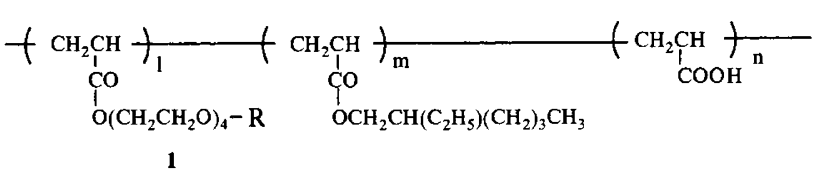

Scheme 1.

measuring increase in weight of $\mathrm{CaCl}_{2}$ covered with adhesive copolymer film. As shown in Table $\Pi$, WVP increased with PEGLA content. Polymer characteristics $\left(M_{w}\right.$ and $M_{w} / M_{n}$ ) of the PEGLA copolymers were similar. PEGLA copolymers thus increase the affinity to water vapor by introducing PEG unit in the copolymer. WVP of the PEGLA copolymer at $40 \mathrm{wt} \%$ PEGLA showed $780 \mathrm{~g}$ $\mathrm{m}^{-2} \mathrm{Day}^{-1}$. Perspiration from human skin at rest is about $600 \mathrm{~g}^{-2} \mathrm{~m} \mathrm{Day}^{-1}$. Therefore PEGLA copolymer is expected to prevent skin irritation by maceration.

Poly(ethylene glycol) alkyl ether acrylates with long alkyl substituent did not form a cross-linked gel in radical polymerization and the copolymer showed high WVP and good adhesive properties as transdermal drug delivery adhesive.

Acknowledgment. We thank NOF corporation for providing the monomers.

\section{REFERENCES}

1. T. A. Peterson, S. M. Wick, and C. Ko., in "Transdermal and Topical Drug Delivery Systems", T. K. Ghosh, W. R. Pfister, and S. I. Yum., Ed.,Interpharm Press,Inc.,Buffalo Grove,Illinois, 1997, p 281.

2. T. Sugii, M. Konno, and S. Wada., Nitto Giho, 27, 42(1989).

3. S. Otsuka, T. Yoshikawa, S. Tokuda, and Y. Ito., JP 57-85318, NITTO DENKO Co.(1983).

4. Y. Hosaka, S. Otsuka., JP 01-297068, NITTO DENKO Co. (1989).

5. G. Bo, B. Wesslen, and K. B. Wesslen., J. Polym. Sci., Part A : Polym. Chem., 30, 1799(1992). 